\title{
Operational and strategic change during temporary turbulence: evidence from the COVID-19 pandemic
}

\author{
Jonathan H. Reed ${ }^{1}$ iD
}

Received: 26 July 2021 / Revised: 23 November 2021 / Accepted: 26 November 2021 / Published online: 2 December 2021

(c) The Author(s), under exclusive licence to Springer Science+Business Media, LLC, part of Springer Nature 2021

\begin{abstract}
Environmental turbulence is a well-studied contingency of relationships involving firm strategy, structure, and performance. However, it is invariably regarded as a present condition of indeterminate duration. Indeed, some industries are regarded turbulent by their nature with little regard for past, present, or future. What of environmental turbulence which is high in level but short in duration? An empirical study is conducted in the COVID-19 context to investigate how firms respond operationally and strategically to what is perceived to be temporary turbulence. Predictors of both operational and strategic change are found to include the level of turbulence and the firm's prior experience making changes. The types of operational change associated with performance improvement are adjusting production levels and budgets/spending. The type of strategic change associated with performance improvement is targeting new customers or markets. A conceptual framework incorporating both the level and duration of turbulence is proposed for future study.
\end{abstract}

Keywords COVID-19 Environmental turbulence $\cdot$ Operational change $\cdot$ Strategic change $\cdot$ Temporary turbulence

\section{Introduction}

The importance of the external environment in strategy formulation and its linkage to organizational outcomes is well known. Early studies by Lawrence and Lorsch (1967), Khandwalla (1972, 1977), Ansoff et al. (1984/2019) and others sought to characterize the environment in ways which would reveal strategies leading to supranormal performance. Today, external analysis is considered the first stage of the strategic management process (Barney and Hesterly 2018; Thompson et al. 2020). Whether assessing broad political, economic and sociocultural trends, or industry-specific forces created by buyers, suppliers and new entrants, strategy must fit the environment in which it is deployed to achieve its goals (Porter 2008; Venkatraman and Prescott 1990).

Environmental turbulence, defined here as the degree of complexity, change, and unpredictability of the external environment, is a particularly important strategic factor (Ansoff et al. 1984/2019; Kipley et al. 2012). Stable

Jonathan H. Reed

jreed2017@fit.edu

1 College of Business, Florida Institute of Technology, $150 \mathrm{~W}$. University Blvd, Melbourne, FL 32901, USA environments encourage the exploitation of existing knowledge to gain efficiencies, while turbulent environments encourage exploration for new knowledge to identify opportunities (March 1991; O'Reilly and Tushman 2013). Stable domains suggest a defender strategy focused on maintaining alignment with the environment and locking out competitors, while turbulent domains suggest a prospector strategy to find and experiment with new responses to environmental trends (Miles et al. 1978; Miles and Snow 2003). Other typologies for both the environment and strategy have been developed and interrelated in the search for competitive advantage (Miller 1988; Mintzberg 1978, 1979).

Various dimensions have been proposed for measuring the turbulence of the environment including complexity, uncertainty, ambiguity, rapidity, visibility, unpredictability, dynamism, heterogeneity, diversity, hostility, and volatility (Ansoff et al. 1984/2019; Bennett and Lemoine 2014; Khandwalla 1977; Kipley et al. 2012; Mintzberg 1979). Once operationalized, studies have focused on environmental turbulence as a moderator of relationships between various organizational constructs (e.g., strategy, structure, entrepreneurial orientation, organizational alignment, strategic agility) and firm performance (Covin and Slevin 1989; Kathuria et al. 2007; Lumpkin and Dess 1996; Miller 1988; Rauch et al. 2009; Reed 2021). 
Surprisingly, most studies involving environmental turbulence assume the condition is a current or ongoing characteristic of the environment. Typical survey items are written in the present tense such as "How would you characterize the external environment within which your firm functions?" (Khandwalla 1977, p. 686). In some cases, the industry as a whole is considered turbulent. The information technology (IT) industry, for example, is frequently studied due to its history of rapid technical advancement which is presumed to continue into the future (Haleblain and Finkelstein 1993; Tallon and Pinsonneault 2011). The wind power industry is considered turbulent (no pun intended) due to its rapid growth and changing government regulations (Zhao et al. 2015). But how long will these trends last? What if technical advancement is expected to slow or regulation is expected to stabilize? Although the external environment may be turbulent currently, the duration of the turbulence may be brief. This study builds on the literature by introducing the notion of turbulence whose duration is anticipated to be short-term. We call this "temporary turbulence." Temporary turbulence might be associated with a specific event such as a terrorist attack, economic recession, or natural disaster. A recent study by Sainidis et al. (2019) investigated environmental turbulence in the context the great recession of 2008 in the UK. However, their focus was on strategic changes made in the aftermath of the recession. We are interested in changes made during what is perceived to be temporary turbulence.

This study answers the call for more management research in the global crisis environment of the COVID-19 pandemic (Muzio and Doh 2020, 2021). COVID-19 created the perfect crucible within which to study temporary turbulence. The onset of the pandemic was quick with the first confirmed U.S. case reported on January 20 and the first confirmed death reported on February 29, 2020 (New England Journal of Medicine 2020). When the World Health Organization declared COVID-19 to be a global pandemic on March 11, the numbers in the U.S. had reached 1,000 confirmed cases and 31 deaths, mostly in Washington state, California, and New York. On March 16, 2020, the White House and the Centers for Disease Control and Prevention (CDC) announced their "15 Days to Slow the Spread" campaign (White House 2020). Many U.S. states and municipalities followed suit issuing lockdown orders generally for 30 days or less. However, by March 26, the number of confirmed cases had risen to 100,000 with 1,000 deaths nationwide, prompting the CDC to extend the "Slow the Spread" campaign another 30 days. Local lockdowns were also incrementally extended. Economically, by the end of June 2020, second quarter U.S. GDP had dropped 31.4 percent (Bureau of Economic Analysis 2021). During this timeframe, despite the rising numbers, the government reported the pandemic was under control and the country may be able to return to normal by Easter, or during the heat of the summer, or by school reopening in the Fall (Kiely et al. 2020). As we know now, the pandemic continued for over a year and reached over 600,000 U.S. deaths in June 2021 (CDC 2021). However, from the early 2020 perspective, the temporary measures and incremental announcements seemed to suggest the pandemic would be short-term. The research question posed by this study is how did businesses respond operationally and strategically to the impacts of COVID-19 if they were perceived to be temporary?

The remainder of this article is organized as follows. In the theory section, the environmental turbulence literature is reviewed and the concept of temporary turbulence is introduced. Operational change and strategic change are also defined so that the types of changes made by businesses during temporary turbulence may be measured. Hypotheses are then developed regarding the predictors of operational and strategic change and their relationships with performance. The methods section describes the quantitative research design, and the results section presents the findings. The final discussion and conclusions section interprets the results including theoretical and practical implications, limitations, and directions for future research.

\section{Theory and hypothesis development}

\subsection{Environmental turbulence}

The origin of environmental turbulence as a construct can be traced to at least Emery and Trist (1965) and their four types of "causal texture" of organizational environments: placid randomized, placid clustered, disturbed reactive, and the turbulent field. ${ }^{1}$ While uncertainty and dynamics increased with each type, the turbulent field was the most complex requiring adaptation to the environment, competitors' moves, and changing causal relationships. In Emery and Trist's turbulence, "the ground is in motion" (p. 26).

While Emery and Trist may have coined the term turbulence in a business sense, subsequent work began unpacking it by exploring its various dimensions. In their seminal work on the organization-environment relationship, Lawrence and Lorsch (1967) examined turbulent environments such as the plastics industry. They identified uncertainty as the defining characteristic of such environments along with three subfactors through which the degree of uncertainty could be measured: 1) the clarity of information available, 2) the understanding of cause-effect relationships, and 3) the time span before definitive feedback on performance was received. They found firm performance in high uncertainty to be

\footnotetext{
${ }^{1}$ Causal texture can be traced to Tolman and Brunswik (1935).
} 
contingent upon the degree to which firms adapted their structural components to the environment (functional differentiation) and the degree to which those differentiated components were integrated within the organization (functional integration).

Building on Lawrence and Lorsch's work, Khandwalla (1970, 1972) identified three dimensions of the external environment: 1) uncertainty described as dynamic and complex, 2) heterogeneity (diversity) having numerous distinctive, internally homogeneous segments, and 3) hostility (or malevolence) a condition of perceived threat to the organization's goals. Khandwalla also proposed an organizational response to each dimension: 1) uncertainty reduction to enable organizational planning, 2) organizational differentiation to adapt differently to each homogenous segment, and 3) organizational integration to coordinate internal activities to overcome the threat, respectively. ${ }^{2}$ While Khandwalla offered only propositions, his dimensions were operationalized by subsequent empirical studies. In a well-known research stream on the relationship between the environment, strategy, and structure, Danny Miller and his colleagues found support for ten common environment-strategy-structure patterns (Miller 1976; Miller and Friesen 1978), for the presence of momentum (resistance to change) in established patterns (Miller and Friesen 1980), and for dramatic change to have a stronger relationship with firm performance than incremental change (Miller and Friesen 1982).

In his study of organizational structures, Mintzberg (1979) extended the number of environmental turbulence dimensions to four: stability (stable to dynamic), complexity (simple to complex), market diversity (integrated to diversified), and hostility (munificent to hostile). Essentially, uncertainty was divided into the two components of dynamic and complex, while diversity and hostility were retained. These dimensions became contingency factors for Mintzberg, helping to motivate his well-known five types of organizational structure: simple, machine bureaucracy, professional bureaucracy, divisionalized form, and adhocracy.

Finally, Ansoff et al. (1984/2019) arrived at five dimensions of environmental turbulence along with a measurement scale. The dimensions are: 1) complexity of the environment, 2) novelty of successive challenges encountered in the environment, 3) rapidity of change in the environment, 4) visibility (unpredictability) of the future, and 5) frequency of shifts in the level of turbulence. The scale defines five levels of turbulence for each dimension: 1) a repetitive environment (no change), 2) expanding (slow incremental change), 3 ) changing (fast incremental change), 4) discontinuous

\footnotetext{
${ }^{2}$ Khandwalla later revised his dimensions to five: turbulence (uncertainty), hostility, diversity, technical complexity, and restrictiveness (Khandwalla 1977).
}

(discontinuous but predictable change) and 5) surprising (discontinuous and unpredictable change). Ansoff's formulation of turbulence further divided the dynamics dimension into subcomponents reflecting the novelty, speed, and unpredictability of change. He also dropped the hostility dimension. None of Ansoff's dimensions presume turbulence is inherently bad or good, malevolent or munificent, harmful or beneficial. Turbulence is at its core simply change, and change presents both opportunity and threat, a phenomenon widely appreciated by entrepreneurs (Gunter 2012; Kirzner 1997).

More recent studies have tailored their turbulence scales to specific industries and contexts while still being predicated on the underlying concepts of uncertainty, speed, and change. For example, in their study of market orientation, Jaworski and Kohli (1993) measured market turbulence and technology turbulence separately with items such as "new customers tend to have product-related needs that are different from those of our existing customers" and "the technology in our industry is changing rapidly" (p. 68). The use of two scales allowed turbulence on the demand-side to be measured separately from turbulence on the supply side. In their study of new product development, Danneels and Sethi (2011) used three scales for the customer turbulence, competitive turbulence, and technological turbulence faced by U.S. manufacturing firms. Other researchers continue to adapt measurement scales for environmental turbulence according to their needs (Chatterjee and Chaudhuri 2021; Lichtenthaler 2009; Sethi and Iqbal 2008; Zhou et al. 2019).

Another recent formulation of turbulence is that of the VUCA environment with the four dimensions of volatility, uncertainty, complexity, and ambiguity (Bennett and Lemoine 2014; Cousins 2018; Millar et al. 2018). While volatility and complexity are treated consistently with the previously described dimensions, uncertainty and ambiguity are distinguished from one another in the VUCA world. Under uncertainty, cause-and-effect are known but the frequency and magnitude of environmental change is not. Under ambiguity, cause-and-effect are unknown as well, creating a lack of knowledge of "the basic rules of the game" (Bennett and Lemoine 2014, p. 313). This distinction follows Emery and Trist's (1965) causal texture. VUCA environments are described as chaotic and putting organizational survival at risk (Bartscht 2015). Researchers have investigated several approaches for dealing with VUCA environments including design thinking (Cousins 2018), organizational ambidexterity (Du and Chen 2018), and backcasting (Thoren and Vendel 2019).

Daniel Kipley, a colleague and co-author of Ansoff, later reflected on the various dimensions of environmental turbulence offered by the literature. "A common definitional thread underpins each offering thus affirming that turbulence is a complex aggregate of three dimensions related to change: dynamism, complexity, and predictability" (Kipley 
et al. 2012, p. 252). Complexity represents the number of environmental elements and their interdependencies. Dynamism represents the frequency and intensity of change in the elements. Predictability represents the uncertainty and ambiguity regarding the cause-and-effect of the change. These three dimensions appear to provide a good basis set. Like VUCA, Kipley also recognized a potential sixth level of Ansoff's turbulence scale representing complete chaos, crisis, or catastrophic conditions (Kipley et al. 2012). However, a single, agreed-upon operationalization of environmental turbulence has not yet emerged in the extant literature.

\subsection{Temporary turbulence}

One factor that appears absent from prior studies is the anticipated duration of environmental turbulence. Lawrence and Lorsch's (1967) time span dimension addresses only feedback time. The concept of frequency (Ansoff et al. 1984/2019) involves time intervals but what if the frequency is expected to decrease? The length of time the turbulence is expected to continue into the future may be an important consideration for firms facing environmental turbulence. This view is consistent with recent research on temporal strategies wherein time-orientation is a significant factor (Ahlstrom and Wang 2021; Lin et al. 2019; Shi et al. 2012).

For example, category 5 Hurricane Michael made landfall on Florida's panhandle in October 2018, inflicting catastrophic damage around Panama City, Mexico Beach, and extending well into Georgia (National Weather Service 2018). Many firms serving the region saw their markets fall into disarray, supply chains disrupted, transportation issues, skyrocketing prices, etc. Other firms found increased demand for their products and services such as water, communications, and construction. However, the environmental turbulence was expected to be temporary. Federal disaster relief and financial assistance arrived quickly and rebuilding was expected within a year. During the recovery, impacted firms modified their internal operations by adjusting their output levels, revising their employee policies regarding safety and time off, identifying alternative suppliers, etc. But should their business strategy be changed too? Should the firm exit the market? Should it develop new products and services addressing new market needs? Should it acquire new resources and capabilities supporting its new products? It is plausible that the answers to these questions are influenced by the anticipated duration of the environmental turbulence. If the turbulence is expected to subside in a month, the firm might simply wait it out. If the turbulence is expected to last three years, the firm might not survive without strategic change.

We adopt the term "temporary turbulence" to describe the phenomenon of anticipated, short duration, environmental turbulence. Note this definition emphasizes the expectation of short duration, not the actual duration which would not be known until the turbulence ends. COVID-19 was expected to be short-term even though it has lingered on. While short duration is intentionally vague, and partly subject to this study, our working definition is less than one year consistent with economic concepts such as current assets/liabilities and fiscal year. Examples of temporary turbulence abound: changes in government regulation that are expected to be undone by the new administration, local real estate bubbles that are expected to end, rising interest rates that are expected to be countered by the Federal Reserve next quarter, and a temporarily grounded fleet of Boeing 737 aircraft. In most cases, some type of organizational response during temporary turbulence is required but these changes are often operational in nature: the new regulation must be applied, the higher interest rate must be paid, and alternative aircraft must be flown. Of greater interest, perhaps, is whether strategic responses are also made during temporary turbulence.

\subsection{Operational and strategic change}

Operations are defined as the internal processes and activities performed by the firm in the production of goods and services (Stevenson 2021). A typology for these activities is required in order to identify the types of operational changes made during temporary turbulence. The value chain is useful for this purpose. In the transformation of input factors to output products and services, most firms conduct activities in the areas of inbound logistics, production, outbound logistics, sales \& marketing, and service (Porter 1985). These primary groupings are often enabled by support activities such as human resources, finance, and procurement. Porter's value chain stages were intentionally generic so as to apply to any industry. But value chain analysis has since been applied widely to reveal industry-specific stages and drivers of value creation. Recent examples include studies of the beef value chain in northern Kenya (Ndiritu 2020), Malaysia's seaweed industry (Nor et al. 2020), geothermal energy in the European Union (Vonsee et al. 2019), offshore wind power in Ireland (Kandrot et al. 2020), silk in Indonesia (Pratama et al. 2019), and pharmaceuticals in the U.S. (Enyinda and Szmerekovsky 2008). Most recently, Gereffi (2020) explored lessons learned from the global medical supplies value chain during COVID-19.

Building on the value chain, researchers have developed new frameworks to enhance our understanding of value chain governance (Gereffi et al. 2005), value chain length and "upstreamness" (Wang et al. 2017), degree of participation in the value stream (Knez et al. 2021), and producerdriven versus buyer-driven value chains (Gereffi 1994). The value chain has also been used as a lens through which to examine other topics such as innovation (Koc and Bozdag 
2017), mergers and acquisitions (Carril-Caccia and Pavlova 2020), and business models (Strakova et al. 2021).

Drawing from the value chain literature, five categories are derived to span the domain of operations for a broad range of companies and identify types of operational change. These are:

- Supply chain, materials, or procurement (inbound)

- Level of production or services (production)

- Sales, marketing or distribution (outbound)

- Employee policies or procedures (human resources)

- Budgets or spending (finance)

Strategy is different from operational effectiveness (Porter 1996). Strategy may be defined as the organization's broad formula for how it is going to compete in the marketplace (Porter 1980). Whereas operations focus on the mechanics of the firm, strategy focuses on the "goals, products and services, resources and capabilities, and the like" (Agarwal and Helfat 2009). The field of strategic management has evolved several schools of thought on strategy, each of which provides a lens through which to view strategic change (Hoskisson et al. 1999; Mintzberg et al. 2009). Porter's positioning school, for example, focuses on how firms position themselves in an industry vis-à-vis competitors by determining which products to sell in which markets (Porter 1980, 1996, 2008; Rumelt 1991). Strategic change from this industry-based view might consist of change in product-market or geographical market focus (Westphal and Fredrickson 2001).

A second school of strategic management is the resourcebased view (RBV) which suggests competitive advantage is tied to the firm's unique set of internal resources and capabilities (Barney 1991; Peteraf 1993; Wernerfelt 1984). Here, products and services are considered the manifestation of the productive application of underlying resources. Strategic change in RBV might consist of changing tangible and intangible assets such as skilled personnel, technology, machinery, efficient procedures, and brand name (Wernerfelt 1984). Kraatz and Zajac (2001) examined four alternative hypotheses regarding the role of organizational resources in strategic change, finding firms with greater resource endowments to have a lower propensity to change.

A third view of strategy is the business model which may be defined as the content, structure, and governance of transactions linking a firm with its constituents in factor and product markets (Amit and Zott 2001). Tracing its roots to transaction cost economics (Williamson 1979), this school seeks to configure its revenue streams and cost structures to enhance the creation and delivery of value (Osterwalder and Pigneur 2010). Uber and Airbnb are oft cited examples of companies which have innovated not on products (automobile transportation or hotel stay) but on the business model for delivering them. Zott and Amit (2008) show the business model is distinct from, but interacts with, product-market strategy.

Finally, several researchers have integrated these views to provide frameworks for assessing strategic change. Ginsberg's (1988) model recognizes the role of both position (productmarket and resource positions) and perspective (configuration of norms and values, production processes, and administrative systems). Zajac et al. (2000) provides a dynamic model categorizing strategic changes by whether they increase or decrease the fit between organizational resources and the environment. Drawing on the strategic change literature, a useful set of categories spanning the strategy domain is derived as follows.

- Key resources or capabilities (resources)

- Types of products or services (products)

- Customer or market focus (markets)

- Revenue or cost structure (business model)

\subsection{Hypothesis development}

Based on the literature review, ten hypotheses are formulated regarding the operational and strategic responses of firms to temporary turbulence. First, it is reasonable that in high environmental turbulence, regardless of its duration, firms are motivated to consider all possible types of change to address organizational impacts. According to Cyert and March (1963):

Any organization as complex as a firm adapts to its environment at many different (but interrelated) levels. It changes its behavior in response to short-run feedback from the environment according to some fairly well-defined rules. It changes rules in response to longer-run feedback according to some more general rules, and so on. (p. 101-102)

However, in low environmental turbulence, firms may choose not to change, especially if the impacts are perceived as temporary. Indeed, several studies have shown environmental turbulence to be a positive moderator of relationships between focal constructs and firm performance (Covin and Slevin 1989; Jaworski and Kohli 1993; Lichtenthaler 2009). We therefore hypothesize that both operational and strategic change are related to temporary turbulence.

H1: Operational change is positively related to the level of temporary turbulence.

$\mathrm{H} 2$ : Strategic change is positively related to the level of temporary turbulence.

Operational change seems nearly mandatory to deal with the immediacies of high turbulence. As previously discussed, firms have little choice but to comply with pandemic 
lockdown orders or hurricane power outages. However, they have significant discretion over changing products, resources, or market focus. Even when strategic change is desired, it may take longer or be more expensive to deploy, and therefore less likely or made to a lesser degree. This leads to the following hypotheses.

H3: Operational change is more likely than strategic change during high temporary turbulence.

H4: The degree of operational change is greater than the degree of strategic change during high temporary turbulence.

The short-term duration of temporary turbulence suggests that operational change may be short-term also. While some operational changes with long-term value may be retained, most would be reversed after the turbulence for which they were designed. This is consistent with research on organizational alignment emphasizing the need to keep organizational elements aligned with the environment (Lawrence and Lorsch 1967; Kathuria et al. 2007). Strategic change, on the other hand, may be less easily reversed after temporary turbulence once strategic commitments and investments have been made.

H5: Operational change is expected to be reversed after high temporary turbulence subsides.

H6: Strategic change is not expected to be reversed after high temporary turbulence subsides.

Unfortunately, firms do not tend naturally towards change. As they grow older and larger, they tend to become more set in their ways due to structural inertia and path dependence (Arthur et al. 1987; Dierickx and Cool 1989; Hannan and Freeman 1984). When they do change, there is also a change cost to overcome. This suggests that firms require sufficient motivation to change their operations or strategy. When faced with environmental turbulence, motivation may come in the form of the perceived magnitude of the turbulence, the degree to which the turbulence impacts the firm financially, and the anticipated duration of the impact. Previous experience making operational and strategic changes may also make the organization more likely to take action during temporary turbulence. These considerations lead to the following hypotheses.

H7: Operational change during high temporary turbulence is positively related to a) the magnitude of the turbulence, b) the financial impact to the firm, c) the anticipated duration of the impact, and d) the frequency of prior operational changes by the firm.

$\mathrm{H} 8$ : Strategic change during high temporary turbulence is positively related to a) the magnitude of the turbulence, b) the financial impact to the firm, c) the anticipated dura- tion of the impact, and d) the frequency of prior strategic changes by the firm.

Finally, for operational or strategic changes to lead to performance improvement during temporary turbulence, they must pay off quickly. On the operations side, reconfiguring the supply chain or distribution channels may take too long or cost too much. Change to employee policies (e.g., reduced work hours, travel restrictions), while quick, may actually decrease firm performance in the short-term. It is therefore hypothesized that the types of operational change most likely to improve performance are adapting the level of production or services to match the new market demand and reducing (or increasing) expenditures accordingly.

H9: Performance improvement due to operational change during high temporary turbulence is positively related to a) change in production levels, and b) change in budget/ spending.

Similarly, on the strategy side, acquiring new resources and developing new products may take too much time and money to make a difference in the short-term. However, selling existing products to new-found customers and changing the business model may be relatively quick and easy. As described by Amit and Zott (2012):

Innovations to improve processes and products, however, are often expensive and time-consuming, requiring a considerable upfront investment in everything from research and development to specialized resources, new plants and equipment, and even entire new business units. Yet future returns on these investments are always uncertain. Hesitant to make such big bets, more companies now are turning toward business model innovation as an alternative or complement to product or process innovation. (p. 41)

This leads to the final hypothesis.

H10: Performance improvement due to strategy change during high temporary turbulence is positively related to a) change in customer/market focus, and b) change in revenue/cost structure.

\section{Methods}

The context of the study was the environmental turbulence created by COVID-19 from March 2020 to March 2021. The target population was managers of U.S. for-profit companies with good visibility into their business operations and strategy. A cross-sectional survey was designed to collect 
Table 1 Study variables

\begin{tabular}{|c|c|c|c|}
\hline Variable & Description & Survey Item & Range \\
\hline IMPMAG & Magnitude of financial impact & $\mathrm{S} 1$ & 0 (none) to 3 (major) \\
\hline IMPNEG & Negative financial impact & S1 & $0 / 1$ \\
\hline IMPPOS & Positive financial impact & $\mathrm{S} 1$ & $0 / 1$ \\
\hline IMPNON & No financial impact & $\mathrm{S} 1$ & $0 / 1$ \\
\hline IMPDUR & Anticipated duration of financial impact & S2 & $1(<3 \mathrm{mo})$ to $4(>12 \mathrm{mo})$ \\
\hline TURB & Level of environmental turbulence & S3-S7 & 1.0 (very low) to 5.0 (very high) \\
\hline $\mathrm{OPCH}$ & Operational change was made & S8 & $0 / 1$ \\
\hline OPCH1 & Change in level of production/services & S9 & $0 / 1$ \\
\hline $\mathrm{OPCH} 2$ & Change in employee policies/procedures & S9 & $0 / 1$ \\
\hline OPCH3 & Change in supply chain/materials/procurement & S9 & $0 / 1$ \\
\hline $\mathrm{OPCH} 4$ & Change in sales/marketing/distribution & S9 & $0 / 1$ \\
\hline OPCH5 & Change in budgets/spending & S9 & $0 / 1$ \\
\hline OPCHDG & Degree of operational change & S10 & 1 (very small) to 5 (very large) \\
\hline OPCHIMP & Perf. improvement from operational change & S11 & 1 (none) to 4 (major) \\
\hline OPCHRT & Expected return to prior operations & S12 & $0 / 1$ \\
\hline OPCHPR & Prior frequency of operational change & S13 & 1 (never) to 4 (frequently) \\
\hline STCH & Strategic change was made & S14 & $0 / 1$ \\
\hline STCH1 & Change in customer/market focus & S15 & $0 / 1$ \\
\hline STCH2 & Change in products/services & $\mathrm{S} 15$ & $0 / 1$ \\
\hline STCH3 & Change in key resources/capabilities & S15 & $0 / 1$ \\
\hline STCH4 & Change in revenue/cost structure & $\mathrm{S} 15$ & $0 / 1$ \\
\hline STCHDG & Degree of strategic change & S16 & 1 (very small) to 5 (very large) \\
\hline STCHIMP & Perf. improvement from strategic change & S17 & 1 (none) to 4 (major) \\
\hline STCHRT & Expected return to prior strategy & $\mathrm{S} 18$ & $0 / 1$ \\
\hline STCHPR & Prior frequency of strategic change & S19 & 1 (never) to 4 (frequently) \\
\hline INDUSTRY & Industry sector & S20 & 1 to 14 NAICS categories \\
\hline AGE & Years in business & $\mathrm{S} 21$ & $1(0-5 \mathrm{yr})$ to $5(>50 \mathrm{yr})$ \\
\hline SIZE & Number of employees & $\mathrm{S} 22$ & $1(1-10 \mathrm{emp})$ to $6(>500 \mathrm{emp})$ \\
\hline
\end{tabular}

the variety of data required by the hypotheses and to access firms of all ages, sizes, and industries. The survey was pilot tested with 20 firms to improve the survey items and statistical methods. The final survey is provided in the Appendix. The survey was timed specifically for April 2021 when COVID-19 vaccines had become widely available in the U.S. and both infection rates and death rates had significantly declined (Johns Hopkins University 2021). U.S. GDP for Q1 of 2021 was also back to within one percent of its preCOVID level in Q4 of 2019 (Bureau of Economic Analysis 2021). This enabled participants to reflect over the preceding year with good recall of the impacts, responses, and performance of their firms.

Table 1 defines the variables used by the study. Environmental turbulence (TURB) was the only latent variable which was operationalized using Ansoff's 5-item scale measuring the degree of complexity, rapidity, novelty, unpredictability, and frequency of change in the external environment (Ansoff et al. 1984/2019). Some variables were reversed from the survey items to range from low to high for analysis.
INDUSTRY was a categorical variable which was converted to 14 dummies (not listed).

The survey was administered using the Momentive (Survey Monkey) online platform due to its large pre-existing panel of full-time U.S. employees. Screening questions were used to qualify participants based on their firm type (for profit), role (manager or senior-level employee) and visibility (high) into their firm's operations, strategy, and performance. Panel members were randomly selected and responses were accepted until the desired sample size was reached. As it is not known how the Momentive panel compares to the true population, the demographics of the qualified participants and their firms were compared to the population for evidence of sample bias. As the survey method favored quick responders, early versus late response bias was also tested. Three types of statistical analysis were conducted: paired sample t-tests to compare the means between corresponding operational and strategic change variables, ANOVA to compare means across industry sectors and between early-late responses, and multiple regression to test the hypotheses involving relationships between variables. 
Table 2 Descriptive Statistics

\begin{tabular}{|c|c|c|c|c|c|c|c|c|c|}
\hline \multirow[b]{2}{*}{ Variable } & \multirow[b]{2}{*}{$N$} & \multirow[b]{2}{*}{ Min } & \multirow[b]{2}{*}{ Max } & \multirow[b]{2}{*}{ Mean } & \multirow[b]{2}{*}{$S D$} & \multicolumn{2}{|c|}{ Skewness } & \multicolumn{2}{|l|}{ Kurtosis } \\
\hline & & & & & & Statistic & $S E$ & Statistic & $S E$ \\
\hline TURB & 656 & 1.0 & 5.0 & 3.5373 & .84430 & -.335 & .095 & .026 & .191 \\
\hline IMPMAG & 656 & 0 & 3 & 1.6494 & .93886 & -.104 & .095 & -.898 & .191 \\
\hline IMPDUR & 656 & 1 & 4 & 2.2637 & .94536 & .431 & .095 & -.674 & .191 \\
\hline $\mathrm{OPCH}$ & 656 & 0 & 1 & .8567 & .35064 & -2.041 & .095 & 2.172 & .191 \\
\hline OPCHPR & 656 & 1 & 4 & 2.7424 & .81537 & -.088 & .095 & -.607 & .191 \\
\hline OPCHDG & 562 & 1 & 5 & 3.7900 & .90278 & -.289 & .103 & -.390 & .206 \\
\hline OPCHRT & 562 & 0 & 1 & .7527 & .43185 & -1.174 & .103 & -.623 & .206 \\
\hline OPCHIMP & 562 & 1 & 4 & 2.8310 & .85379 & -.480 & .103 & -.285 & .206 \\
\hline OPCH1 & 562 & 0 & 1 & .5125 & .50029 & -.050 & .103 & -2.005 & .206 \\
\hline $\mathrm{OPCH} 2$ & 562 & 0 & 1 & .6833 & .46561 & -.790 & .103 & -1.381 & .206 \\
\hline ОРCH3 & 562 & 0 & 1 & .4128 & .49278 & .355 & .103 & -1.881 & .206 \\
\hline OPCH4 & 562 & 0 & 1 & .3577 & .47974 & .596 & .103 & -1.651 & .206 \\
\hline OPCH5 & 562 & 0 & 1 & .4057 & .49146 & .385 & .103 & -1.858 & .206 \\
\hline STCH & 656 & 0 & 1 & .7165 & .45106 & -.963 & .095 & -1.076 & .191 \\
\hline STCHPR & 656 & 1 & 4 & 2.6387 & .87316 & -.057 & .095 & -.716 & .191 \\
\hline STCHDG & 470 & 1 & 5 & 3.7830 & .88323 & -.121 & .113 & -.685 & .225 \\
\hline STCHRT & 470 & 0 & 1 & .7277 & .44564 & -1.026 & .113 & -.951 & .225 \\
\hline STCHIMP & 470 & 1 & 4 & 2.9702 & .81508 & -.610 & .113 & .053 & .225 \\
\hline STCH1 & 470 & 0 & 1 & .5809 & .49395 & -.329 & .113 & -1.900 & .225 \\
\hline STCH2 & 470 & 0 & 1 & .5234 & 49998 & -.094 & .113 & -2.000 & .225 \\
\hline STCH3 & 470 & 0 & 1 & .3979 & .48998 & .419 & .113 & -1.833 & .225 \\
\hline STCH4 & 470 & 0 & 1 & .2809 & .44989 & .978 & .113 & -1.047 & .225 \\
\hline AGE & 656 & 1 & 5 & 3.1433 & 1.24086 & -.168 & .095 & -.964 & .191 \\
\hline SIZE & 656 & 1 & 6 & 3.8216 & 1.82440 & -.252 & .095 & -1.346 & .191 \\
\hline IMPNEG & 656 & 0 & 1 & .6524 & .47656 & -.642 & .095 & -1.593 & .191 \\
\hline IMPPOS & 656 & 0 & 1 & .2302 & .42127 & 1.285 & .095 & -.350 & .191 \\
\hline IMPNON & 656 & 0 & 1 & .1174 & .32212 & 2.383 & .095 & 3.690 & .191 \\
\hline
\end{tabular}

\section{Results}

Of 1,324 randomly selected individuals, 656 (49.5\%) complete responses from qualified participants were received. Table 2 provides the descriptive statistics. Nearly all ordinal and continuous (non-boolean) variables demonstrated normal distributions with low skewness and kurtosis values. Only firm size showed excess kurtosis (-1.346) outside the desired range of \pm 1.0 , but not enough to require transformation.

Tables 3 and 4 provide the correlations. Both Pearson and Spearman correlations were calculated with minimal differences in the results, as would be expected for normal distributions (De Winter et al. 2016). Pearson's $r$ is shown in the tables. Environmental turbulence (TURB) showed good reliability with a Cronbach's alpha of 0.801 and confirmatory factor analysis identifying only one principal component with an eigenvalue greater than 1.0 , providing a 55.8 percent average variance explained.

Sample bias was checked by comparing the demographics of the participants and their firms with population data from the U.S. Census Bureau and U.S. Bureau of Labor Statistics. 56.1 percent of the participants were employed by small businesses (<100 employees) compared to 53.7 percent reported by the Census Bureau (2021a) for the U.S. as a whole in 2018. 57.3 percent of the participants' firms were 20 years old or younger compared to 59.5 percent reported by the Census Bureau (2021b). The median participant income was $\$ 75,000$ compared to $\$ 76,600$ for the management, business, and financial operations occupations across all industries in Q1 of 2021 (Bureau of Labor Statistics 2021a). The median age group of participants was 45-60 years compared to the median age of 46.9 years for management occupations across all industries (Bureau of Labor Statistics 2021b). The participants were also well-balanced across all major regions of the U.S. (e.g., New England, Mid-Atlantic, Southern Atlantic, etc.) and by gender (nearly 50/50 percent). This consistency between the sample and U.S. population suggests bias was not an issue in the study. In addition, following Armstrong and Overton (1977), the sample was subdivided into early and late response waves and ANOVA was used to test for differences in means. None of the focal variables showed 


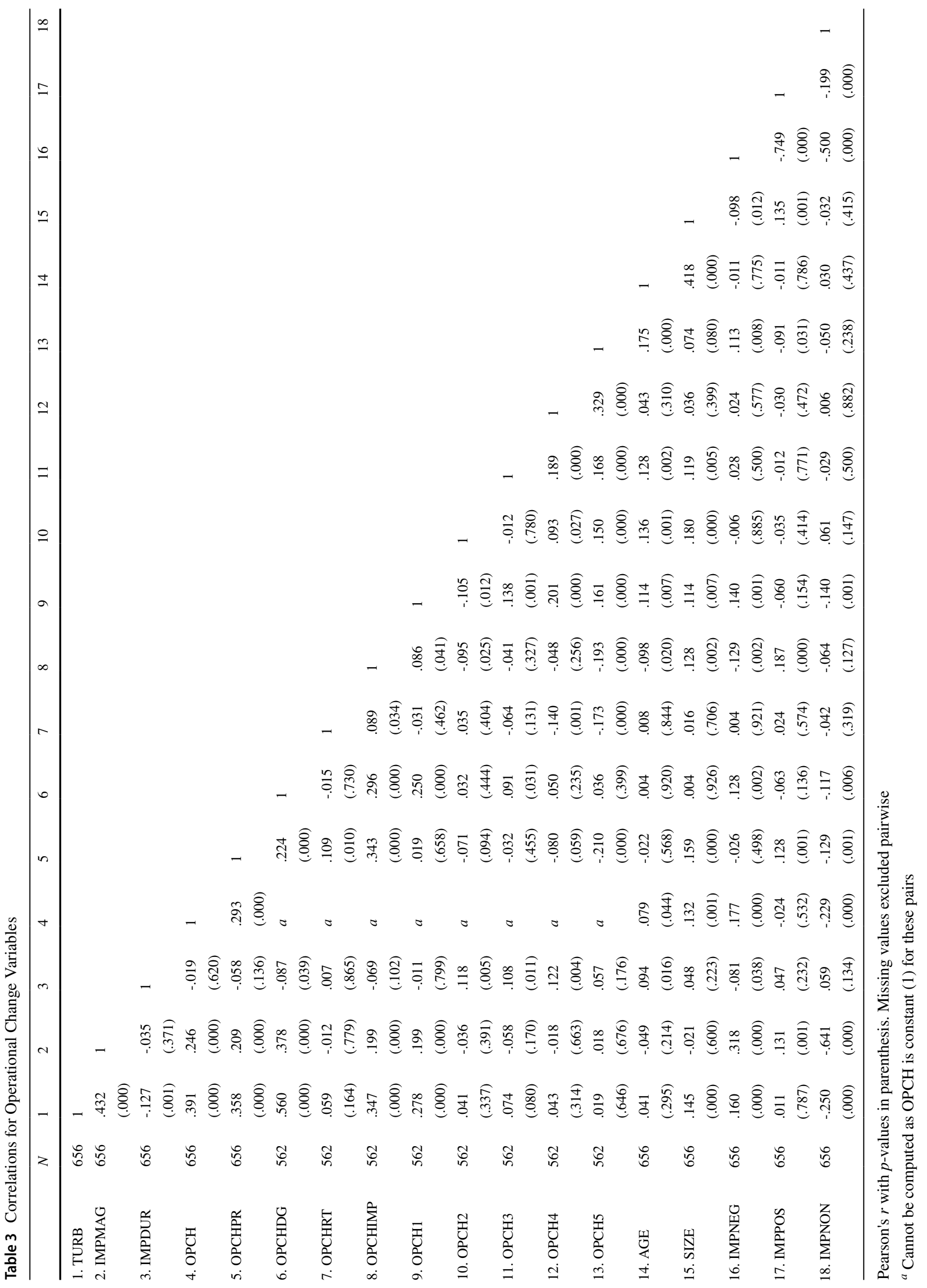




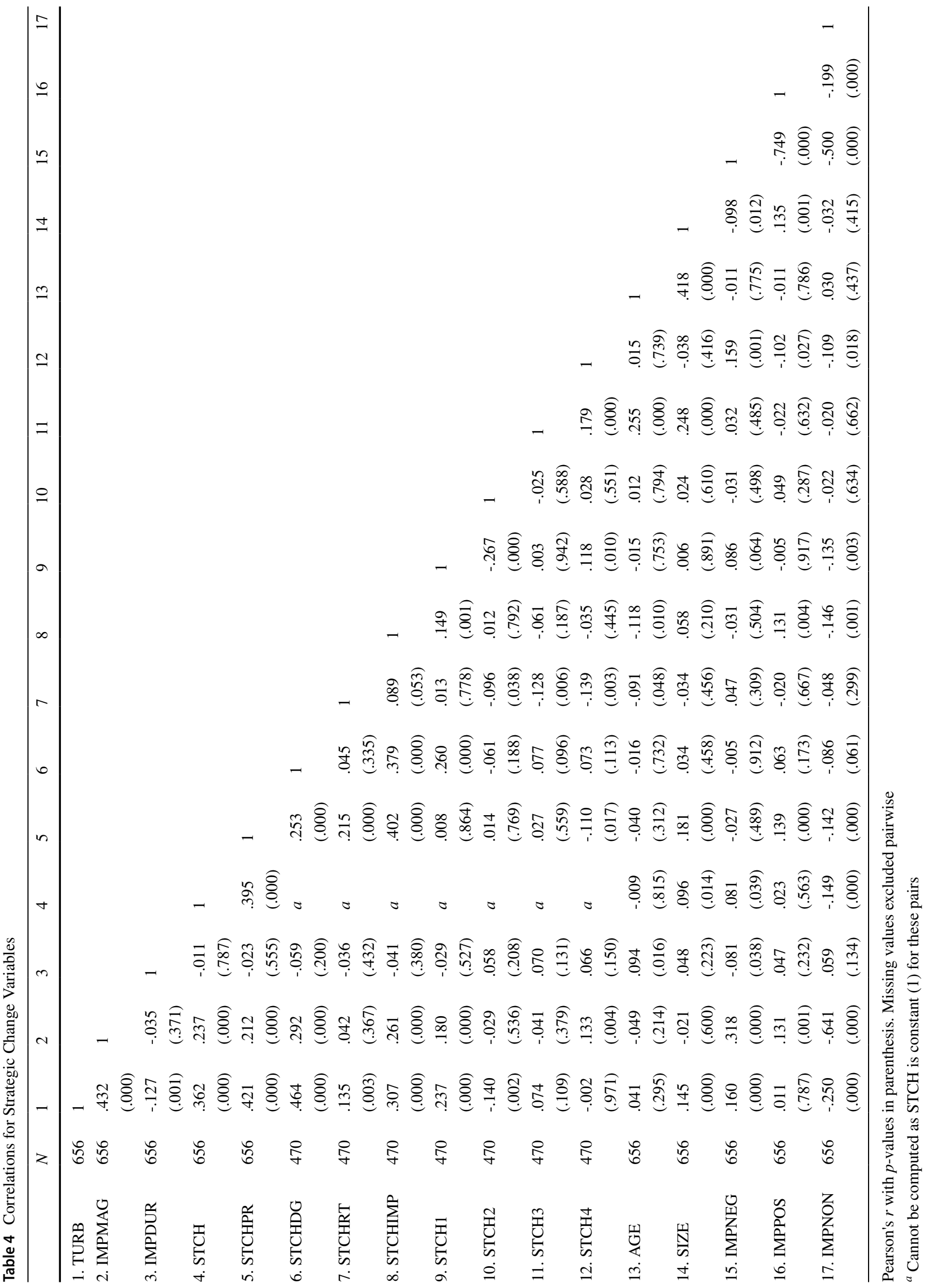


Fig. 1 Degree of financial impact due to COVID-19 $(N=656)$

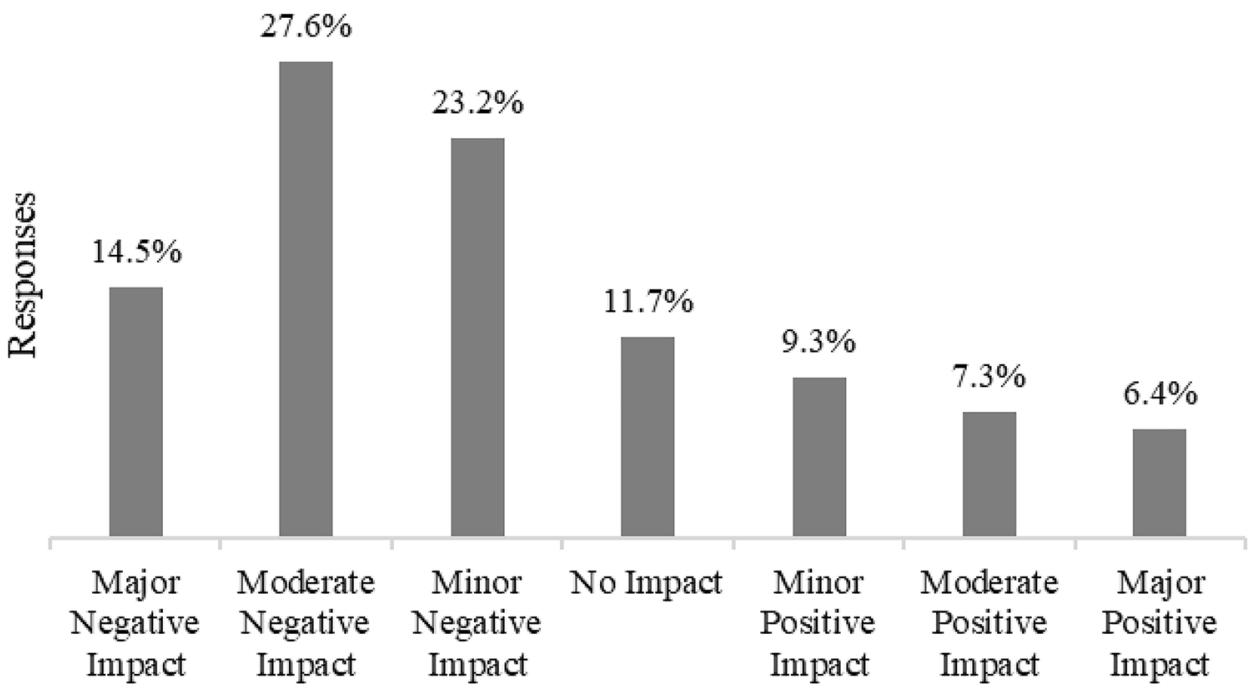

statistically significant differences between the two groups, suggesting nonresponse and early response bias were not an issue either.

Since the same source (survey participant) was used for all data items, common method variance was tested using Harman's single factor test (Podsakoff et al. 2003). For each regression, a principal component analysis was conducted on the subjective dependent and independent variables to see if one underlying component (namely, a common rater) explained a large proportion of the variance. The highest loading components ranged from only 24.8 percent to 30.3 percent average variance explained, suggesting common method bias was not an issue.

\subsection{Temporary turbulence}

The mean value of TURB (3.54) on Ansoff's scale indicates COVID-19 was perceived as medium-to-high turbulence in the external environment. The mean value of IMPMAG (1.65) indicates a moderate level of financial impact to the firms. Figure 1 shows the magnitude and direction of the impact. Notably, 23.0 percent reported a positive impact to their financials due to COVID-19. This is likely due to increased demand for products and services in segments such as healthcare, medical supplies, IT systems, online services, home delivery, etc. In fact, all industry sectors except Energy/Utilities reported positive as well as negative impacts. As the direction of the impact may influence the way firms respond to COVID-19, it was used as a control variable in subsequent analysis.

Regarding the temporary nature of the turbulence, Fig. 2 shows the duration of the financial impact anticipated by the firms at the onset of COVID-19. 66.2 percent of the participants expected the impact to last six months or less and 86.3 percent of the participants expected the impact to last one year or less, confirming that the COVID-19 turbulence was widely viewed as short-term.

\subsection{Change in operations and strategy}

$562(85.7 \%)$ of the participants reported operational changes (OPCH) and $470(71.7 \%)$ of the participants reported strategic changes (STCH) were made by their firms due to COVID-19. Both OPCH $(r=0.391, p<0.001)$ and STCH $(r=0.362, p<0.001)$ were positively correlated with TURB. These results (and the regressions below) support hypotheses $\mathrm{H} 1$ and $\mathrm{H} 2$. Table 5 shows the differences in means between paired operational and strategic change variables. The difference between $\mathrm{OPCH}$ and STCH was significant $(t=7.909, d f=655, p<0.001)$ supporting hypothesis $\mathrm{H} 3$ that operational change was more likely. The degree of change was also higher for operational change

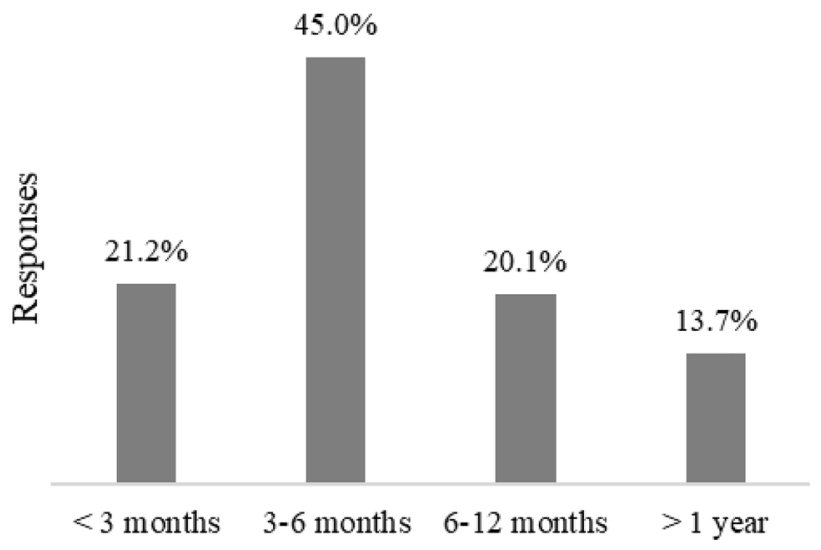

Fig. 2 Anticipated duration of financial impact due to COVID-19 $(N=656)$ 
Table 5 Paired sample t-tests between operational and strategic means

\begin{tabular}{lcrrcrrrc}
\hline Pairs & $N$ & Mean 1 & Mean 2 & Mean Difference & $t$ & $d f$ & Sig & Cohen's $d$ \\
\hline OPCH_STCH & 656 & .8567 & .7165 & .14024 & 7.909 & 655 & .000 & .309 \\
OPCHDG_STCHDG & 442 & 3.9231 & 3.8167 & .10633 & 2.658 & 441 & .008 & .126 \\
OPCHRT_STCHRT & 442 & .7421 & .7330 & .00905 & .516 & 441 & .606 & .025 \\
OPCHPR_STCHPR & 656 & 2.7424 & 2.6387 & .10366 & 3.627 & 655 & .000 & .142 \\
OPCHIMP_STCHIMP & 442 & 2.9593 & 2.9977 & -.03846 & -1.040 & 441 & .299 & -.049 \\
\hline
\end{tabular}

Missing values excluded listwise
(OPCHDG) than for strategic change (STCHDG) $(t=2.658$, $d f=441, p=0.008$ ) supporting hypothesis $\mathrm{H} 4$.

74.2 percent of the participants expected their firms to return to their prior operations (OPCHRT) after COVID-19 subsided, supporting hypothesis H5. However, 73.3 percent of the participants expected to return to their prior strategy (STCHRT) also. This difference was insignificant and does not support hypothesis H6. Apparently, strategic change is as likely to be undone as operational change following temporary turbulence. The last two lines of the table show that prior to COVID-19, firms changed their operations more frequently than their strategy $(t=3.627, d f=655$, $p<0.001$ ), but the difference in performance improvement due to operational versus strategic change was insignificant. Of the statistically significant mean differences, only the first, the likelihood of changing operations versus strategy, showed a practically meaningful effect size of 0.309 as measured by Cohen's $d$ (Cohen 1992).

Tables 6 and 7 show the types of operational and strategic changes made by the firms. Here, participants could select more than one type if needed, allowing each of the percentages to range from 0 to 100 percent. All the categories of change were well-utilized by firms, as expected. The performance improvements associated with these changes are examined in a later section.

\subsection{Predictors of change}

Hypotheses $\mathrm{H} 7$ and $\mathrm{H} 8$ were tested by regressing operational change and strategic change on the same four independent variables: environmental turbulence (TURB), financial impact magnitude (IMPMAG), anticipated impact duration (IMPDUR), and prior change (OPCHPR or STCHPR). Four covariates were used to control for firm age (AGE), firm size (SIZE), and direction of the financial impact (IMPNEG, IMPPOS).

Table 8 shows the results for operational change. When $\mathrm{OPCH}$ was used as the dependent, three of the four control variables were significant accounting for 7.7 percent of the variance explained. Of the hypothesized predictors, perceived level of turbulence $(\beta=0.284, p<0.001)$ and prior operational change $(\beta=0.177, p<0.001)$ were significant, adding 13.4 percent to the variance explained. Turbulence had the larger effect. Also, the decision to change operations was more strongly related to negative financial impact than to positive financial impact. When the degree of operational change (OPCHDG) was instead used as the dependent, the relationship with turbulence became stronger $(\beta=0.454, p<0.001)$, the financial impact predictor became significant $(\beta=0.253, p<0.001)$, and the proportion of variance explained increased to 0.364 . Thus, more significant changes were made when the turbulence was high and there was a direct financial impact. Overall, the results provide support for hypotheses $\mathrm{H} 7 \mathrm{a}, \mathrm{H} 7 \mathrm{~b}$, and $\mathrm{H} 7 \mathrm{~d}$, but not H7c. Apparently, operational change is associated with temporary turbulence regardless of its anticipated duration.

Table 9 shows that the results for strategic change are similar to operational change. With STCH as the dependent, the same three control variables were significant and accounted for 3.3 percent of the variance. The same two predictors, turbulence $(\beta=0.199, p<0.001)$ and prior change

Table 6 Operational changes in response to COVID-19 by type

\begin{tabular}{lll}
\hline Type & Count & Percent \\
\hline Level of Production or Services & 288 & $43.9 \%$ \\
Employee Policies or Procedures & 384 & $58.5 \%$ \\
Supply Chain, Materials, or Procurement & 232 & $35.4 \%$ \\
Sales, Marketing, or Distribution & 201 & $30.6 \%$ \\
Budgets or Spending & 228 & $34.8 \%$ \\
None & 94 & $14.3 \%$
\end{tabular}

Multiple changes allowed, $N=656$

Table 7 Strategic changes in response to COVID-19 by type

\begin{tabular}{lll}
\hline Type & Count & Percent \\
\hline Customer or Market Focus & 273 & $41.6 \%$ \\
Types of Products or Services & 246 & $37.5 \%$ \\
Key Resources or Capabilities & 187 & $28.5 \%$ \\
Revenue or Cost Structure & 132 & $20.1 \%$ \\
None & 186 & $28.4 \%$ \\
\hline
\end{tabular}

Multiple changes allowed, $N=656$ 
Table 8 Predictors of operational change and degree of change

\begin{tabular}{llllll}
\hline & \multicolumn{3}{l}{ OPCH } & & \multicolumn{2}{l}{ OPCHDG } \\
\cline { 2 - 3 } \cline { 5 - 6 } \cline { 5 - 6 } & Controls & Predictors & & Controls & Predictors \\
\hline AGE & $.034(.407)$ & $.053(.175)$ & $.004(.924)$ & $.046(.225)$ \\
SIZE & $.122(.004)$ & $.046(.249)$ & $.016(.734)$ & $-.033(.399)$ \\
IMPNEG & $.361(.000)$ & $.225(.001)$ & $.217(.002)$ & $-.147(.037)$ \\
IMPPOS & $.230(.000)$ & $.110(.095)$ & $.109(.121)$ & $-.202(.003)$ \\
TURB & & $.284(.000)$ & & $.454(.000)$ \\
IMPMAG & & $.005(.919)$ & & $.253(.000)$ \\
IMPDUR & & $.033(.351)$ & & $-.026(.459)$ \\
OPCHPR & & $.177(.000)$ & & $.082(.024)$ \\
$R$ & .277 & .459 & .145 & .603 \\
$R^{2}$ & .077 & .211 & .021 & .364 \\
Delta $R^{2}$ & .077 & .134 & .021 & .343 \\
$S E$ & .33791 & .31339 & .89647 & .72511 \\
$p$ & .000 & .000 & .019 & .000 \\
\hline
\end{tabular}

Coefficients are standardized with $p$-values in parenthesis, $N=562$

( $\beta=0.291, p<0.001$ ), were significant adding 17.8 percent to the variance explained. However, with strategic change, prior experience changing strategy had a greater effect than the perceived level of turbulence. With the degree of strategic change (STCHDG) as the dependent, financial impact once again became significant $(\beta=0.188, p=0.001)$ and the predictors added 23.9 percent to the variance explained. Overall, these results provide support for hypotheses H8a, $\mathrm{H} 8 \mathrm{~b}$, and $\mathrm{H} 8 \mathrm{~d}$, but not H8c. The anticipated duration of financial impact does not appear to influence strategic change either.

Table 9 Predictors of strategic change and degree of change

\begin{tabular}{llllll}
\hline & \multicolumn{3}{l}{ STCH } & \multicolumn{2}{l}{ STCHDG } \\
\cline { 2 - 3 } \cline { 5 - 6 } & Controls & Predictors & & Controls & \multicolumn{1}{l}{ Predictors } \\
\hline AGE & $-.054(.207)$ & $-.015(.698)$ & & $-.030(.555)$ & $.007(.881)$ \\
SIZE & $.117(.007)$ & $.026(.509)$ & $.041(.431)$ & $.000(.994)$ \\
IMPNEG & $.219(.000)$ & $.012(.866)$ & $.129(.098)$ & $-.155(.069)$ \\
IMPPOS & $.170(.004)$ & $-.028(.669)$ & $.160(.041)$ & $-.086(.302)$ \\
TURB & & $.199(.000)$ & & $.369(.000)$ \\
IMPMAG & & $.090(.068)$ & & $.188(.001)$ \\
IMPDUR & & $.027(.446)$ & & $-.021(.603)$ \\
STCHPR & & $.291(.000)$ & & $.110(.012)$ \\
$R$ & .182 & .459 & .106 & .501 \\
$R^{2}$ & .033 & .211 & .011 & .251 \\
Delta $R^{2}$ & .033 & .178 & .011 & .239 \\
$S E$ & .44485 & .40312 & .88199 & .77124 \\
$p$ & .000 & .000 & .258 & .000 \\
\hline
\end{tabular}

Coefficients are standardized with $p$-values in parenthesis, $N=470$
Table 10 Performance improvement due to operational change

\begin{tabular}{lll}
\hline & \multicolumn{2}{l}{ OPCHIMP } \\
\cline { 2 - 3 } & Controls & Predictors \\
\hline AGE & $-.176(.000)$ & $-.148(.001)$ \\
SIZE & $.187(.000)$ & $.191(.000)$ \\
IMPNEG & $.055(.423)$ & $.044(.518)$ \\
IMPPOS & $.208(.002)$ & $.187(.006)$ \\
OPCH1 (Production Level) & & $.111(.009)$ \\
OPCH2 (Employee Policy) & & $-.065(.120)$ \\
OPCH3 (Supply Chain) & & $-.032(.445)$ \\
OPCH4 (Sales/Marketing) & & $.003(.950)$ \\
OPCH5 (Budget/Spending) & & $-.173(.000)$ \\
$R$ & .270 & .344 \\
$R^{2}$ & .073 & .119 \\
Delta $R^{2}$ & .073 & .046 \\
$S E$ & .82500 & .80805 \\
$p$ & .000 & .000 \\
\hline
\end{tabular}

Coefficients are standardized with $p$-values in parenthesis, $N=562$

\subsection{Performance improvement}

Hypothesis H9 was tested by regressing performance improvement due to operational change (OPCHIMP) on the types of operational change with the same control variables. The results in Table 10 show significant effects for the controls. As firms age they appear less likely to improve due to operational change, while as firms become larger they appear more likely to improve due to operational change. Performance improvement is also positively related with positive financial impact as one might expect. Amongst the hypothesized predictors, change in level of production $(\mathrm{OPCH} 1)$ is positively related to performance improvement ( $\beta=0.111, p=0.009)$, supporting hypothesis H9a. However, change in budget/spending (OPCH5) is negatively related to performance improvement $(\beta=-0.173, p<0.001)$ running counter to hypothesis $\mathrm{H} 9 \mathrm{~b}$ which proposed a positive relationship.

Hypothesis $\mathrm{H} 10$ was tested by regressing performance improvement due to strategic change (STCHIMP) on the types of strategic change and controls. Table 11 shows the results with control variables providing similar effects as before. However, performance improvement due to strategic change is related to both negative and positive financial impact. Amongst the hypothesized predictors, only the change in customer/market focus (STCH1) is positively related to performance improvement $(\beta=0.149, p=0.002)$ supporting hypothesis H10a but not H10b.

Note the coefficients of determination $\left(R^{2}\right)$ for these performance improvement regressions are somewhat low at 0.119 for the operational changes and 0.079 for the strategic changes. These values meet Ferguson's (2009) $R^{2}$ rule of 
Table 11 Performance improvement due to strategic change

\begin{tabular}{lll}
\hline & \multicolumn{2}{l}{ STCHIMP } \\
\cline { 2 - 3 } & \multicolumn{1}{l}{ Controls } & \multicolumn{1}{l}{ Predictors } \\
\hline AGE & $-.164(.001)$ & $-.153(.003)$ \\
SIZE & $.117(.022)$ & $.120(.020)$ \\
IMPNEG & $.206(.007)$ & $.182(.018)$ \\
IMPPOS & $.277(.000)$ & $.251(.001)$ \\
STCH1 (Market Focus) & & $.149(.002)$ \\
STCH2 (Products/Services) & & $.044(.343)$ \\
STCH3 (Resources/Capabilities) & & $-.044(.358)$ \\
STCH4 (Revenue/Cost Structure) & & $-.043(.359)$ \\
$R$ & .237 & .281 \\
$R^{2}$ & .056 & .079 \\
Delta $R^{2}$ & .056 & .023 \\
$S E$ & .79526 & .78892 \\
$p$ & .000 & .000 \\
\hline
\end{tabular}

Coefficients are standardized with $p$-values in parenthesis, $N=470$

thumb of 0.04 as the recommended minimum effect size for "practically" significant events in social science data, and Cohen's (1992) $f^{2}$ rule of thumb of 0.02 for a small effect size in multiple regression. (An $R^{2}$ of 0.079 equates to an $f^{2}$ of 0.086 ). Nonetheless, there are clearly other contributors to performance improvement from operational and strategic change during high temporary turbulence that were not modelled.

\subsection{Industry effects}

Table 12 provides the ANOVA results comparing the means of five variables across the 14 industry sectors. The betweengroup differences were significant in all cases but strategic change (STCH). For example, the level of turbulence (TURB) and magnitude of financial impact (IMPMAG) were highest in the Arts/Entertainment/Recreation, Hotel/Food/ Beverage, and Education sectors. However, the decision to change operations $(\mathrm{OPCH})$ was highest in the Education, Transportation, and Manufacturing sectors. Although not shown due to space limitations, the industry dummies were also included as controls in the above regressions with negligible changes to the findings. The main effects found by the study appear robust to the industry effects.

\section{Discussion and conclusions}

This study suggests that the duration of environmental turbulence matters. Temporary turbulence is defined as anticipated short-term turbulence in the external environment. This construct adds a temporal aspect to previous studies involving the role of environmental turbulence. Ten hypotheses regarding the responses of firms to temporary turbulence were evaluated in the context of the COVID-19 pandemic. Overall, there appear to be more similarities than
Table 12 Turbulence, impact, duration, and change means by industry sector

\begin{tabular}{lllllll}
\hline Industry Sector & Count & TURB & IMPMAG & IMPDUR & OPCH & STCH \\
\hline Arts, Entertainment, Recreation & 31 & $\mathbf{3 . 9 0 9 7}$ & $\mathbf{2 . 2 2 5 8}$ & 2.1935 & .8710 & .7097 \\
Hotel, Food, Beverage & 56 & $\mathbf{3 . 7 8 3 9}$ & $\mathbf{1 . 8 2 1 4}$ & 2.3036 & .8929 & $\mathbf{. 7 6 7 9}$ \\
Retail, Wholesale Trade & 71 & 3.4986 & 1.6197 & 2.3239 & .8873 & .7183 \\
Construction & 41 & 3.5561 & 1.7805 & 2.0976 & .7317 & .7317 \\
Manufacturing & 77 & 3.5182 & 1.5584 & 2.2987 & $\mathbf{. 9 0 9 1}$ & .7403 \\
Technical, Professional Services & 98 & 3.4714 & 1.5102 & 2.2041 & .8061 & .7245 \\
Finance or Insurance & 58 & 3.5828 & 1.6552 & 2.3103 & .8793 & $\mathbf{. 7 4 1 4}$ \\
Healthcare, Social Assistance & 64 & 3.4406 & 1.6563 & 2.3594 & .9062 & .5937 \\
Education & 34 & $\mathbf{3 . 7 1 1 8}$ & $\mathbf{1 . 8 2 3 5}$ & 1.9412 & $\mathbf{. 9 7 0 6}$ & $\mathbf{. 8 2 3 5}$ \\
Transportation & 15 & 3.2533 & 1.5333 & 1.8667 & $\mathbf{. 9 3 3 3}$ & .6667 \\
Real Estate & 20 & 3.2400 & 1.4000 & $\mathbf{2 . 4 5 0 0}$ & .7500 & .6500 \\
Energy, Utilities & 7 & 3.5143 & 1.2857 & 1.4286 & .8571 & .7143 \\
Agriculture, Forestry, Mining & 5 & 2.9200 & 1.2000 & $\mathbf{2 . 4 0 0 0}$ & .6000 & .6000 \\
Government, Public Admin & 10 & 3.4000 & 1.2000 & $\mathbf{3 . 4 0 0 0}$ & .9000 & .7000 \\
Other & 69 & 3.4899 & 1.6377 & 2.3188 & .7826 & .7101 \\
Total & 656 & 3.5373 & 1.6494 & 2.2637 & .8567 & .7165 \\
$F$ & & 1.563 & 1.789 & 2.255 & 1.722 & .626 \\
Sig & & .085 & .037 & .005 & .047 & .845 \\
Eta & & .182 & .194 & .217 & .190 & .116 \\
Eta Squared & .033 & .038 & .013 & .036 & .013 \\
\hline
\end{tabular}

Top three industry means for each variable in bold 
differences between operational change and strategic change during high temporary turbulence. Both types of change were likely, but operational change was more likely. Both types of change were associated with the perceived level of environmental turbulence and prior experience making changes. However, operational change was driven more by the turbulence level, and strategic change was driven more by the prior experience. When looking at the degree of change made by firms, the magnitude of the financial impact became a significant factor. The greater the financial impact, the greater the degree of both operational and strategic change.

While all five types of operational change were made, those associated with performance improvement were change in level of production (or services) and change in budget or spending. These two appear to go hand in hand, as reducing production would generally require less spending on production factors such as labor, materials, etc. However, the spending change was negatively related with performance improvement. This may be due to respondents associating cutbacks with reduced revenues or profits rather than lessening the degree of the reduction (a relative improvement).

All four types of strategic change were also made but only one, change in customer or market focus, was associated with performance improvement. Taking existing products or services to new customers where the demand is higher during COVID-19 may be less expensive and quicker to accomplish than developing new products or changing key resources.

The control variables were also essential due to their significance in the regression models. For example, firm age was found to be negatively related with performance improvement and firm size was found to be positively related with performance improvement during temporary turbulence. These findings are consistent with several past studies (Abatecola et al. 2012; Coad et al. 2013; Pervan et al. 2017). The 14 industry sectors also varied with respect to the level of turbulence, financial impact, expected duration of the impact, and operational change. These findings agree with government data on the differential impact of COVID19 by industry (Bureau of Labor Statistics 2020).

In summary, five hypotheses regarding the use of operational and strategic change during high temporary turbulence were supported (H1, H2, H3, H4, H5). Four hypotheses regarding the predictors of operational and strategic change and performance improvement were partially supported (H7, H8, H9, H10). And one hypothesis regarding strategic change being more permanent was not supported (H6). This last finding is consistent with recent research on strategic agility which suggests strategy can be changed quickly too (Clauss et al. 2019; Doz and Kosonen 2008; Reed 2021; Weber and Tarba 2014).

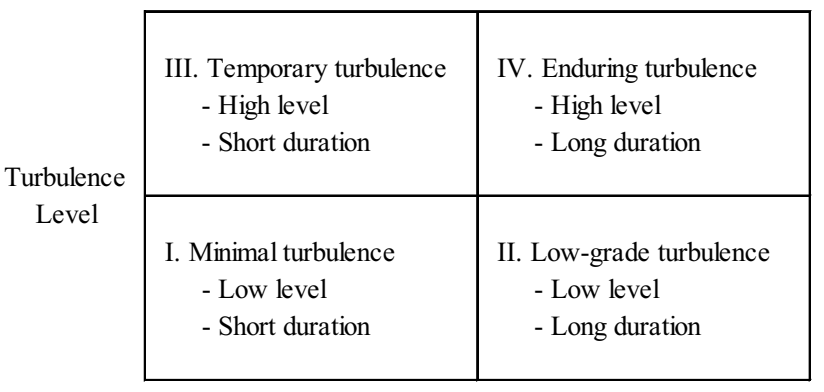

Turbulence Duration

Fig. 3 Framework combining level and duration of environmental turbulence

\subsection{Implications for theory}

Is it possible that duration represents an additional dimension of environmental turbulence? This study treated duration as a separate construct, different from the level of turbulence. Figure 3 shows how the level of turbulence and the duration of turbulence may be combined in a $2 \times 2$ conceptual framework. Through its focus on COVID-19, this study addressed Quadrant III, temporary turbulence, where the turbulence level is high ( $>3.0$ on Ansoff's scale) and the duration is short ( $<1$ year). However, recognizing duration as a separate dimension opens the theoretical aperture to allow consideration of the other three quadrants.

Minimal turbulence (Quadrant I) is defined as environmental turbulence which is low in both level and duration. This quadrant might also be called the stable environment, one with which we are familiar and expect exploitation as opposed to exploration to be rewarded (Danneels and Sethi 2011; March 1991; O'Reilly and Tushman 2013). Enduring turbulence (Quadrant IV) might also be familiar, as without consideration of duration, environmental turbulence is usually presumed to be lasting or of indefinite duration, as in the IT industry case. Quadrant IV is therefore the traditional high turbulence environment. Low-grade turbulence (Quadrant II), like temporary turbulence, is an interesting new quadrant revealed by the framework. Here we might consider the turbulence to be at a low level but bothersome, nagging, and unending. Like a low-grade fever, the patient is not ready to go see the doctor but is unhappy with the current state, nonetheless. Examples of low-grade turbulence might include high interest rates, unfavorable demographic trends, strong competition, or regulatory restrictions. The level-duration framework offers a new typology for environmental turbulence which considers these two dimensions of turbulence separately and may prove useful for future studies.

Alternatively, following Ansoff's model, duration could be measured from 1 (short) to 5 (long) and included within the formulation of the turbulence construct itself (Ansoff 
et al. 1984/2019). Ansoff's scale would be amended to include six factors: the complexity, novelty, rapidity, unpredictability, frequency, and duration of change in the environment. This expanded latent variable would now include an explicit temporal factor, making the highest level of turbulence one that is anticipated to remain in place long-term. This seems consistent with the traditional view of environmental turbulence which, by making no claim on time, presumes the turbulence to be enduring. Conceptually, this approach draws a straight line from the lower left quadrant to the upper right quadrant of Fig. 3. As a result, it leaves the other two quadrants lost in the continuum from stability to turbulence, possibly losing explanatory power in favor of simplicity.

Whether modelled as a separate dimension or as a combined construct, this study complements existing literature by incorporating anticipated duration into the conceptualization of environmental turbulence. New studies may be conceived to explore the expanded domain (quadrants), apply the broadened Ansoff or VUCA scales, focus on the micro level (e.g., leadership changes, M\&A events), and address environmental transitions (e.g., from temporary to enduring), with the objective of revealing new relationships involving operations, strategy, and performance.

\subsection{Implications for practice}

Several practical implications for managers are apparent. First, a significant proportion (23.0\%) of the survey participants reported positive financial impacts to their companies from COVID-19. This serves as a reminder that opportunities may be identified and exploited even when environmental turbulence appears high or short-lived.

Second, while all nine categories of change examined by the study were found to be exercised by the firms during COVID-19, only three were associated with performance improvement. These were: 1) adjusting the level of production or services (lower or higher) to match the revised level of demand, 2) likewise adjusting the budget or level of spending, and 3) targeting new customers or markets. These three changes may be viewed as levers for managers to pull when seeking to survive or improve during temporary turbulence.

Third, it is interesting that most firms in the study expected to return to their prior operations and strategies after the pandemic. Two interpretations may prove useful here. Given the high expectation of only temporary turbulence, the changes might have been designed specifically for short-term use. Such changes might not be suitable for longterm continuation. Additionally, six of the nine categories of change were not associated with performance improvement. Firms would have little reason to continue these nonproductive changes either. Note as the survey asked about the expectation of returning to prior operations and strategy, it is not known whether these reversals actually took place.

Finally, prior experience with changing operations and strategy was found to be a strong contributor to firms' decisions to make changes during high temporary turbulence. Without this experience, managers might choose instead to wait it out. A mindset of continuous operational improvement (Galeazzo et al. 2017) and strategic renewal (Agarwal and Helfat 2009) may therefore prove valuable during challenging times.

\subsection{Limitations}

Three limitations of this study are noted. First, the survey method provided subjective data only. Participants provided their personal views of their firms' financial impact, responses, and performance during COVID-19. While participants were managers or senior-level employees with insight into their firms' operations and strategy, the reliability of the data may be improved if acquired from or combined with archival or objective sources.

Second, the effect of government subsidies during COVID-19 was not considered. For example, the federal Paycheck Protection Program (PPP) doled out \$799.8 billion in reduced interest rate and/or forgivable loans through May of 2021 (Small Business Administration 2021). While 87.1 percent of the loans were in the amount of $\$ 50$ thousand or less, it is possible that these funds influenced participants' responses to the financial impact and other survey items, biasing them in a favorable direction.

Third, the types of operational and strategic changes found related to performance improvement should be interpreted with caution. While statistically significant, the proportion of the variance explained in the performance findings was modest and other variables may come into play. For example, the speed with which changes are made, how well they are implemented, and how much they cost might add explanatory value. It may not be only what you change but how you change it.

\subsection{Future research directions}

Apart from addressing the above limitations, future research is suggested on the theoretical implications of temporary turbulence. Both approaches for incorporating the duration of turbulence with the level of turbulence should be further investigated. Each of the quadrants of the $2 \times 2$ framework in Fig. 3 could be studied in alternative contexts. A study focused on Quadrant III, low-grade turbulence, would help fill in our understanding of the full framework. The six-factor version of Ansoff's model could also be easily operationalized and tested. These studies would advance our understanding and modelling of environmental turbulence. 
It was also surprising that the anticipated duration of the financial impact was not found to be a significant predictor of either operational or strategic change in this study. This may be due to the narrow range of the variable. The COVID19 data set may have been too short-term in expected duration. Temporary turbulence with a somewhat longer horizon such as a trade war, social unrest, or economic recession (e.g., two to three years) may provide greater variation in anticipated duration through which relationships might be found.

Overall, the contribution of this study is to suggest that turbulence need not be considered a time invariant condition of the environment, but one whose anticipated duration also plays a role in the operation and strategy of firms.

\section{Appendix 1 Survey items}

S1. How much was your company financially impacted (negatively or positively) by COVID-19?

$\bigcirc$ Major negative impact $\bigcirc$ Moderate negative impact $\bigcirc$ Minor negative impact $\bigcirc$ No impact.

$\bigcirc$ Minor positive impact $\bigcirc$ Moderate positive impact $\bigcirc$ Major positive impact.

S2. At the onset of COVID-19, how long did your company think the impacts would last?

$\bigcirc<3$ months $\bigcirc 3-6$ months $\bigcirc$ 6-12 months $\bigcirc>1$ year.

S3. How complex was your company's external environment during COVID-19? The term "environment" is defined as the political, economic, social, technological, ecological, and legal factors affecting your company.

$\bigcirc$ Very complex $\bigcirc$ Complex $\bigcirc$ Moderately complex $\bigcirc$ Slightly complex $\bigcirc$ Not Complex.

S4. How rapidly did challenges arise in the external environment during COVID-19?

$\bigcirc$ Very rapidly $\bigcirc$ Rapidly $\bigcirc$ Moderately rapidly $\bigcirc$ Slightly rapidly $\bigcirc$ Not rapidly.

S5. How novel (new or unusual) were the challenges in the external environment during COVID-19?

$\bigcirc$ Very novel $\bigcirc$ Novel $\bigcirc$ Moderately novel $\bigcirc$ Slightly novel $\bigcirc$ Not novel.

S6. How unpredictable was the external environment during COVID-19?

$\bigcirc$ Very unpredictable $\bigcirc$ Unpredictable $\bigcirc$ Moderately unpredictable $\bigcirc$ Slightly unpredictable $\bigcirc$ Not unpredictable.

S7. How frequently did the external environment shift between stability and instability during COVID-19?

$\bigcirc$ Very frequently $\bigcirc$ Frequently $\bigcirc$ Moderately frequently $\bigcirc$ Slightly frequently $\bigcirc$ Not frequently.

S8. Did your company change its internal operations due to COVID-19? The term "operations" is defined as the internal functions, processes, and activities that are performed by the company. $\bigcirc$ Yes $\bigcirc$ No.

S9. What aspect of its operations did your company change? You may select more than one answer.

$\bigcirc$ Level of production or services $\bigcirc$ Employee policies or procedures $\bigcirc$ Supply chain, materials, or procurement.

$\bigcirc$ Sales, marketing, or distribution $\bigcirc$ Budgets or spending.

S10. What was the overall degree of operational change?

$\bigcirc$ Very large $\bigcirc$ Large $\bigcirc$ Moderate $\bigcirc$ Small $\bigcirc$ Very small.

S11. How much did the operational change improve your company's performance during COVID-19?

$\bigcirc$ Major improvement $\bigcirc$ Moderate improvement $\bigcirc$ Minor improvement $\bigcirc$ No improvement.

S12. Do you think your company will mostly return to its previous operations after COVID-19 subsides?

$\bigcirc$ Yes $\bigcirc$ No.

S13. How often did your company change its internal operations prior to COVID-19?

$\bigcirc$ Frequently $\bigcirc$ Occasionally $\bigcirc$ Rarely $\bigcirc$ Never.

S14. Did your company change its business strategy due to COVID-19? The term "strategy" is defined as the company's broad approach for achieving competitive advantage in the marketplace.

$\bigcirc$ Yes $\bigcirc$ No.

S15. What aspect of its strategy did your company change? You may select more than one answer.

$\bigcirc$ Customer or market focus $\bigcirc$ Types of products or services $\bigcirc$ Key resources or capabilities $\bigcirc$ Revenue or cost structure.

S16. What was the overall degree of strategy change?

$\bigcirc$ Very large $\bigcirc$ Large $\bigcirc$ Moderate $\bigcirc$ Small $\bigcirc$ Very small.

S17. How much did the strategy change improve your company's performance during COVID-19?

$\bigcirc$ Major improvement $\bigcirc$ Moderate improvement $\bigcirc$ Minor improvement $\bigcirc$ No improvement.

S18. Do you think your company will mostly return to its previous strategy after COVID-19 subsides?

$\bigcirc$ Yes $\bigcirc$ No.

S19. How often did your company change its business strategy prior to COVID-19?

$\bigcirc$ Frequently $\bigcirc$ Occasionally $\bigcirc$ Rarely $\bigcirc$ Never.

S20. In what industry is your company?

$\bigcirc$ Arts, entertainment, or recreation $\bigcirc$ Hotel, food, or beverage $\bigcirc$ Retail or wholesale trade $\bigcirc$ Construction.

$\bigcirc$ Manufacturing $\bigcirc$ Technical or professional services $\bigcirc$ Finance $\bigcirc$ Healthcare $\bigcirc$ Education $\bigcirc$ Real estate.

$\bigcirc$ Government or public administration $\bigcirc$ Other.

S21. How many years has your company been in business?

$\bigcirc 0-5$ years $\bigcirc$ 6-10 years $\bigcirc 11-20$ years $\bigcirc 21-50$ years $\bigcirc>50$ years. 
S22. How many employees does your company have?

○ 1-10 employees $\bigcirc$ 11-20 employees $\bigcirc$ 21-50 employees $\bigcirc$ 51-100 employees $\bigcirc 101-500$ employees.

O > 500 employees.

\section{Declarations}

Conflict of interest The authors have no relevant financial or non-financial interests to disclose.

\section{References}

Abatecola G, Cafferata R, Poggesi S (2012) Arthur Stinchcombe's "liability of newness": contribution and impact of the construct. J Manag Hist 18(4):402-418

Agarwal R, Helfat CE (2009) Strategic Renewal of Organizations Organ Sci 20(2):281-293

Ahlstrom D, Wang LC (2021) Temporal strategies and firms' speedy responses to COVID-19. J Manag Stud 58(2):592-596

Amit R, Zott C (2001) Value creation in e-business. Strateg Manag J 22:493-520

Amit R, Zott C (2012) Creating value through business model innovation. MIT Sloan Manag Rev 53(3):41-49

Ansoff HI, Kipley D, Lewis AO, Helm-Stevens R, Ansoff R (2019) Implanting Strategic Management, 3rd edition. Palgrave Macmillan, Switzerland. (Original work published 1984)

Armstrong JS, Overton TS (1977) Estimating nonresponse bias in mail surveys. J Mark Res 14:396-402

Arthur WB, Ermoliev YM, Kaniovski YM (1987) Path-dependent processes and the emergence of macrostructure. Eur J Oper Res 30:294-303

Barney J (1991) Firm resources and sustained competitive advantage. J Manag 17(1):99-120

Barney JB, Hesterly WS (2018) Strategic Management and Competitive Advantage: Concepts and Cases, 6th edition. Pearson, Harlow, UK

Bartscht J (2015) Why systems must explore the unknown to survive in VUCA environments. Kybern 44(2):253-270

Bennett N, Lemoine JG (2014) What a difference a word makes: Understanding threats to performance in a VUCA world. Bus Horiz 57(3):311-317

Bureau of Economic Analysis (2021) Gross Domestic Product, 1st Quarter 2021 (Second Estimate); Corporate Profits, 1st Quarter 2021 (Preliminary Estimate). https://www.bea.gov/news/2021/grossdomestic-product-1st-quarter-2021-second-estimate-corporateprofits-1st-quarter. Accessed 22 Jun 2021

Bureau of Labor Statistics (2020) Geographic Impact of COVID-19 in BLS Surveys by Industry. https://www.bls.gov/opub/mlr/ 2020/article/geographic-impact-of-covid-19-in-bls-surveysby-industry.htm. Accessed 22 Jun 2021

Bureau of Labor Statistics (2021a) Median Usual Weekly Earnings by Occupation and Sex, Not Seasonally Adjusted. https://www. bls.gov/webapps/legacy/cpswktab4.htm. Accessed 9 Jul 2021

Bureau of Labor Statistics (2021b) Household Data Annual Averages: Employed Persons by Detailed Occupation and Age. https://www.bls.gov/cps/cpsaat11b.pdf. Accessed 9 Jul 2021

Carril-Caccia F, Pavlova E (2020) Mergers and acquisitions \& trade: A global value chain analysis. World Econ 43:586-614

CDC (2021) COVID Data Tracker. U.S. Centers for Disease Control and Prevention. https://covid.cdc.gov/covid-data-tracker/\#datatrackerhome. Accessed 15 June 2021
Census Bureau (2021a) 2018 Business Dynamics Statistics Datasets: Establishment Size. https://www.census.gov/data/datasets/timeseries/econ/bds/bds-datasets.html. Accessed 9 Jul 2021

Census Bureau (2021b) 2018 Business Dynamics Statistics Datasets: Establishment Age. https://www.census.gov/data/datasets/timeseries/econ/bds/bds-datasets.html. Accessed 9 Jul 2021

Chatterjee S, Chaudhuri R (2021) Supply chain sustainability during turbulent environment: Examining the role of firm capabilities and government regulation. Oper Manag Res. https://doi.org/10. 1007/s12063-021-00203-1

Clauss T, Abebe M, Tangpong C, Hock M (2019) Strategic agility, business model innovation, and firm performance: an empirical investigation. IEEE Trans Eng Manag. https://doi.org/10.1109/ TEM.2019.2910381

Coad A, Segarra A, Teruel M (2013) Like milk or wine: Does firm performance improve with age? Struct Chang Econ Dyn 24:173-179

Cohen J (1992) A Power Primer Quant Methods Psychol 112(1):155-159

Cousins B (2018) Design thinking: Organizational learning in VUCA environments. Acad Strateg Manag J 17(2):1-18

Covin JG, Slevin DP (1989) Strategic management of small firms in hostile and benign environments. Strateg Manag J 10(1):75-87

Cyert RM, March JG (1963) A behavioral theory of the firm. PrenticeHall, Englewood Cliffs, NJ

Danneels E, Sethi R (2011) New product exploration under environmental turbulence. Organ Sci 22(4):1026-1039

De Winter JCF, Gosling SD, Potter JP (2016) Comparing the Pearson and Spearman correlation coefficients across distributions and sample sizes. Psychol Methods 21(3):273-290

Dierickx I, Cool K (1989) Asset stock accumulation and sustainability of competitive advantage. Manag Sci 35(12):1504-1511

Doz YL, Kosonen M (2008) Fast Strategy: How Strategic Agility Will Help You Stay Ahead of the Game. Wharton School Publishing, Edinburgh Gate, UK

Du J, Chen Z (2018) Applying organizational ambidexterity in strategic management under a "VUCA" environment: Evidence from high tech companies in China. Int J Innov Stud 2(2018):42-52

Emery FE, Trist EL (1965) The causal texture of organizational environments. Hum Relat 18:21-32

Enyinda CI, Szmerekovsky J (2008) Sense and respond supply chain: A prescription for mitigating vulnerability in the U.S pharmaceutical value chain. J Glob Bus Issues 2(2):95-103

Ferguson CJ (2009) An effect size primer: A guide for clinicians and researchers. Prof Psychol Res Pract 40(5):532-538

Galeazzo A, Furlan A, Vinelli A (2017) The organizational infrastructure of continuous improvement - an empirical analysis. Oper Manag Res 10:33-46

Gereffi, G (1994) The organization of buyer-driven global commodity chains: How U.S. retailers shape overseas production networks. In: Gereffi G, Korzeniewicz M (eds) Commodity chains and global capitalism. Praeger, Westport, CT, pp 95-122

Gereffi G (2020) What does the COVID-19 pandemic teach us about global value chains? The case of medical supplies. J Int Bus Polic 3:287-301

Gereffi G, Humphrey J, Sturgeon T (2005) The governance of global value chains. Rev Int Polit Econ 12(1):78-104

Ginsberg A (1988) Measuring and modelling changes in strategy: Theoretical foundations and empirical directions. Strateg Manag J 9:559-575

Gunter FR (2012) A simple model of entrepreneurship for principles of economics courses. J Econ Educ 43(4):386-396

Haleblain J, Finkelstein S (1993) Top management team size, CEO dominance, and firm performance: The moderating roles of environmental turbulence and discretion. Acad Manag J 36(4):844-863

Hannan MT, Freeman J (1984) Structural inertia and organizational change. Am Sociol Rev 49:149-164 
Hoskisson RE, Hitt MA, Wan WP, Yiu D (1999) Theory and research in strategic management: Swings of a pendulum. J Manag 25(3):417-456

Jaworski BJ, Kohli AK (1993) Market orientation: antecedents and consequences. J Mark 57(3):53-70

Johns Hopkins University (2021) COVID-19 Dashboard by the Center for Systems Science and Engineering. https://www.arcgis. com/apps/dashboards/bda7594740fd40299423467b48e9ecf6. Accessed 12 Jul 2021

Kandrot S, Cummins V, Jordan D, Murphy J (2020) Economic and employment impacts of offshore wind for Ireland: A value chain analysis. Int J Green Energ 17(11):687-696

Kathuria R, Joshi MP, Porth SJ (2007) Organizational alignment and performance: past, present and future. Manag Decis 45(3):503-517

Khandwalla PN (1970) The Influence of Techno-Economic Environment on the Organizational Structure of Firms. Dissertation, Carnegie-Mellon University

Khandwalla PN (1972) Environment and its impact on the organization. Int Stud Manag Organ, Fall 1972:297-313

Khandwalla PN (1977) The Design of Organizations. Harcourt Brace Jovanovich, New York

Kiely E, Robertson L, Rieder R, Gore D (2020) Timeline of Trump's COVID-19 Comments. https://www.factcheck.org/2020/10/ timeline-of-trumps-covid-19-comments/. Accessed 22 Jun 2021

Kipley D, Lewis A, Jewe R (2012) Entropy - disrupting Ansoff's five levels of environmental turbulence. Bus Strateg Ser 13(6):251-262

Kirzner IM (1997) Entrepreneurial discovery and the competitive market process: An Austrian approach. J Econ Lit 35(1):60-85

Knez K, Jaklic A, Stare M (2021) An extended approach to value chain analysis. Econ Struct 10(13). https://doi.org/10.1186/ s40008-021-00244-6

Koc T, Bozdag E (2017) Measuring the degree of novelty of innovation based on Porter's value chain approach. Eur J Oper Res 257:559-567

Kraatz MS, Zajac EJ (2001) How organizational resources affect strategic change and performance in turbulent environments: Theory and evidence. Organ Sci 12(5):632-657

Lawrence PR, Lorsch JW (1967) Organization and Environment. Harvard Business School Press, Boston

Lichtenthaler U (2009) Absorptive capacity, environmental turbulence, and the complementarity of organizational learning processes. Acad Manag J 52(4):822-846

Lin Y, Shi W, Prescott JE, Yang H (2019) In the eye of the beholder: Top managers' long-term orientation, industry context, and decision-making processes. J Manag 45(8):3114-3145

Lumpkin GT, Dess GG (1996) Clarifying the entrepreneurial orientation construct and linking it to performance. Acad Manag Rev 21(1):135-172

March JG (1991) Exploration and exploitation in organizational learning. Organ Sci 2(1):71-87

Miles RE, Snow CC (2003) Organizational Strategy, Structure, and Process. Stanford University Press, Stanford, CA

Miles RE, Snow CC, Meyer AD, Coleman HJ Jr (1978) Organizational strategy, structure, and process. Acad Manag Rev, July 1978:546-562

Millar CCJM, Groth O, Mahon JF (2018) Management innovation in a VUCA world: Challenges and recommendations. Calif Manag Rev 61(1):5-14

Miller D (1976) Strategy making in context: Ten empirical archetypes. Dissertation, McGill University

Miller D (1988) Relating Porter's business strategies to environment and structure: Analysis and performance implications. Acad Manag J 31(2):280-308

Miller D, Friesen PH (1978) Archetypes of Strategy Formulation Manag Sci 24(9):921-933
Miller D, Friesen PH (1980) Momentum and revolution in organizational adaptation. Acad Manag J 23(4):591-614

Miller D, Friesen PH (1982) Structural change and performance: Quantum versus piecemeal-incremental approaches. Acad Manag J 25(4):867-892

Mintzberg H (1978) Patterns in Strategy Formation Manag Sci 24(9):934-948

Mintzberg H (1979) The Structuring of Organizations. Prentice-Hall, Englewood Cliffs, NJ

Mintzberg H, Ahlstrand B, Lampel J (2009) Strategy safari: Your complete guide through the wilds of strategic management. Prentice Hall, London

Muzio D, Doh JP (2020) Introduction to the COVID-19 commentaries. J Manag Stud 57(8):1725-1726

Muzio D, Doh J (2021) COVID-19 and the future of management studies. Insights from leading scholars. J Manag Stud 58(5):1371-1377

National Weather Service (2018) Catastrophic Hurricane Michael Strikes Florida Panhandle October 10, 2018. https://www. weather.gov/tae/HurricaneMichael2018. Accessed 22 Jun 2021

Ndiritu SW (2020) Beef value chain analysis and climate change adaptation and investment options in the semi-arid lands of northern Kenya. J Arid Env. https://doi.org/10.1016/j.jaridenv. 2020.104216

New England Journal of Medicine (2020) First case of 2019 novel coronavirus in the United States. New Engl J Med 382(10):929-936

Nor AM, Gray TS, Caldwell GS, Stead SM (2020) A value chain analysis of Malaysia's seaweed industry. J Appl Phycol 32:2161-2171

O'Reilly CA, Tushman ML (2013) Organizational ambidexterity: past, present, and future. Acad Manag Perspect 27(4):324-338

Osterwalder A, Pigneur Y (2010) Business model generation. John Wiley \& Son, Hoboken, NJ

Pervan M, Pervan I, Curak M (2017) The influence of age on firm performance: Evidence from the Croatian food industry. J East Eur Res Bus and Econ. https://doi.org/10.5171/2017.618681

Peteraf MA (1993) The cornerstones of competitive advantage: a resource-based view. Strat Manag J 14(3):179-191

Podsakoff PM, MacKenzie SB, Lee J-Y, Podsakoff NP (2003) Common method biases in behavioral research: A critical review of the literature and recommended remedies. J Appl Psychol 88(5):879-903

Porter ME (1980) Competitive Strategy: Techniques for Analyzing Industries and Competitors. Free Press, New York

Porter ME (1985) Competitive Advantage: Creating and Sustaining Superior Performance. Free Press, New York

Porter ME (1996) What is strategy? Harv Bus Rev, November-December 1996:61-78

Porter ME (2008) The five competitive forces that shape strategy. Harv Bus Rev 86(1):78-93

Pratama AG, Supratman S, Makkarennu M (2019) Examining forest economies: A case study of silk value chain analysis in Wajo District. For Soc 3(1):22-33

Rauch A, Wiklund J, Lumpkin GT, Frese M (2009) Entrepreneurial orientation and business performance: An assessment of past research and suggestions for the future. Entrep Theory Pract 33(3):761-787

Reed JH (2021) Strategic agility and the effects of firm age and environmental turbulence. J Strateg Manag 14(2):129-149

Rumelt RP (1991) How much does industry matter? Strateg Manag J 12:167-185

Sainidis E, Robson A, Heron G (2019) Environmental turbulence and the role of business functions in the manufacturing strategy debate: the case of UK-based SMEs and the Great Recession. J Gen Manag 44(4):190-208

Sethi R, Iqbal Z (2008) Stage-gate controls, learning failure, and adverse effect on novel new products. J Mark 72:118-134 
Shi W, Sun J, Prescott JE (2012) A temporal perspective of merger and acquisition and strategic alliance initiatives: Review and future direction. J Manag 38(1):164-209

Small Business Administration (2021) Paycheck Protection Program (PPP) Report: Approvals through 05/31/2021. https://www.sba. gov/document/report-paycheck-protection-program-weeklyreports-2021. Accessed $10 \mathrm{Jul} 2021$

Stevenson WJ (2021) Operations Management, 14th edn. McGrawHill, New York

Strakova J, Simberova I, Partlova P, Vachal J, Zich R (2021) The value chain as the basis of business model design. J Compet 13(2):135-151

Tallon PP, Pinsonneault A (2011) Competing perspectives on the link between strategic information technology alignment and organizational agility: Insights from a mediation model. MIS Q 35(2):463-486

Thompson AA, Peteraf MA, Gamble JE, Strickland AJ III (2020) Crafting and Executing Strategy: The Quest for Competitive Advantage, 22nd edn. McGraw-Hill, New York

Thoren K, Vendel M (2019) Backcasting as a strategic management tool for meeting VUCA challenges. J Strateg Manag 12(2):298-312

Tolman EC, Brunswik E (1935) The organism and the causal texture of the environment. Psychol Rev 42:43-77

Venkatraman N, Prescott JE (1990) Environment-strategy coalignment: An empirical test of its performance implications. Strateg Manag J 11(1):1-23

Vonsee B, Crijns-Graus W, Liu W (2019) Energy technology dependence - A value chain analysis of geothermal power in the EU. Energy 178:419-435
Wang Z, Wei S-J, Yu X, Zhu K (2017) Characterizing global value chains: production length and upstreamness. Working paper 23261, National Bureau of Economic Research, Cambridge, MA

Weber Y, Tarba SY (2014) Strategic agility: A state of the art. Cal Manag Rev 56(3):5-12

Wernerfelt B (1984) A resource based view of the firm. Strateg Manag J 5(2):171-180

Westphal JD, Fredrickson JW (2001) Who directs strategic change? Director experience, the selection of new CEOs, and a change in corporate strategy. Strateg Manag J 22(12):1113-1137

White House (2020) 15 Days to Slow the Spread. https://trumpwhitehouse. archives.gov/articles/15-days-slow-spread/. Accessed 22 Jun 2021

Williamson OE (1979) Transaction cost economics: The governance of contractual relations. J Law Econ 22(2):233-261

Zajac EJ, Kraatz MS, Bresser RKF (2000) Modeling the dynamics of strategic fit: A normative approach to strategic change. Strateg Manag J 21:429-453

Zhao ZY, Zhu J, Zuo H (2015) Flexibility of wind power industry chain for environmental turbulence: A matching model study. Renew Energy 83(2015):375-383

Zhou Y, Shu C, Jiang W, Gao S (2019) Green management, firm innovations, and environmental turbulence. Bus Strateg Env 28:567-581

Zott C, Amit R (2008) The fit between product market strategy and business model: Implications for firm performance. Strat Manag J 29:1-26

Publisher's Note Springer Nature remains neutral with regard to jurisdictional claims in published maps and institutional affiliations. 